\title{
7. REFLEXIONES SOBRE UNA HIPOTÉTICA REFORMA CONSTITUCIONAL DEL CAPÍTULO ॥ DEL TÍTULO I DE LA CONSTITUCIÓN
}

\author{
GREGORIO CÁMARA VILLAR \\ Catedrático de Derecho Constitucional \\ y \\ AGUSTÍN RUIZ ROBLEDO \\ Profesor Titular de Derecho Constitucional \\ Universidad de Granada
}




\section{SUMARIO}

INTRODUCCIÓN.-I. SOBRE LOS NOMBRES.-II. SOBRE LA SISTEMÁTICA.III. EVALUACIÓN Y PROPUESTAS DE REFORMAS DEL ARTICULADO: arts. 14, $15,16,18,19,20,21,26,27,29,30,31,33,34,35$ у 38. 


\title{
7. REFLEXIONES SOBRE UNA HIPOTÉTICA REFORMA CONSTITUCIONAL DEL CAPÍTULO II DEL TITTULO I DE LA CONSTITUCIÓN
}

\author{
POR \\ GREGORIO CÁMARA VILLAR \\ Catedrático de Derecho Constitucional \\ y \\ AGUSTÍN RUIZ ROBLEDO \\ Profesor Titular de Derecho Constitucional
}

Universidad de Granada

INTRODUCCIÓN

Decía Aristóteles, refiriéndose a las imposibles propuestas de Platón, que «el esfuerzo inútil produce melancolía». Y quizás nosotros corremos el riesgo de caer en ella al proponer la reforma de algunos artículos del Capítulo II, porque si referirse a la modificación de disposiciones constitucionales ordinarias es ya una tarea casi inútil, dada la negativa de los principales partidos políticos a tocar la Constitución, completamente inaccesible parece reformar artículos protegidos por el procedimiento agravado, como son todos los de la Sección $1^{a}$. Y más si se tiene en cuenta que la valoración que en el tiempo transcurrido desde su aprobación cabe hacer de la funcionalidad del Capítulo II en su conjunto no puede ser más que muy positiva, éxito que el constituyente debe compartir en buena medida con la labor interpretadora de la doctrina y, muy especialmente, del Tribunal Constitucional. 
Para huir de este esfuerzo melancólico hay un tentador camino: proponer nuevas redacciones que satisfagan los deseos personales más ideales, de tal forma que como el resultado sería el mismo -en ningún caso se moverá una coma de la CE- a uno le quede siempre la pequeña satisfacción de haber defendido tesis que serían muy bien aceptadas en Utopía, aunque tenga conciencia de que hoy por hoy sean impracticables en la terrenal España. Un sólo ejemplo: ¿no sería maravilloso que la dignidad humana y la fraternidad universal nos llevasen a un artículo 19 que estableciese la libertad de entrada y permanencia de todos los extranjeros que lo quisieran?

Sin embargo, no hemos cedido a la tentación y hemos preferido opciones si no fáciles sí posibles, con la remota esperanza de que si alguna vez se abriese un proceso de reforma pudieran ser barajadas por el legislador constituyente. Es decir, nos hemos esforzado en seguir otro consejo del gran ARISTÓTELES: "las suposiciones pueden hacerse a voluntad, pero sin imposibles».

Antes de hacer nuestras enmiendas (lo más técnicas que hemos sabido y siempre en la línea de profundización de los valores constitucionales) nos gustaría dejar claro que el Capítulo II del Título I tiene defectos evidentes de sistemática y terminología que la doctrina se ha encargado de criticar, pero gracias en parte a esa misma crítica, casi siempre hecha con la finalidad uti valeat, a la poca trascendencia de algunos errores (¿qué importancia puede tener en la práctica que se constitucionalice antes la libertad de negociación colectiva que la libertad de empresa?) y a la fundamental labor de integración del Tribunal Constitucional, lo cierto es que se puede decir de la Constitución que si a veces yerra en las formas nunca lo hace en el fondo.

Si a eso se le suma que la mayoría de los artículos que debemos analizar forman parte de los que JELLINEK denominara el status libertatis y se encuentran muy consolidados en toda la cultura jurídica europea, no nos queda otro remedio que concluir que no parece necesario una reforma constitucional que tuviese como único objeto tratar las materias que afrontamos en este trabajo. Dada la poca importancia de nuestras propuestas sería, si se nos permite acudir al refranero, como matar moscas a cañonazos. 


\section{SOBRE LOS NOMBRES}

Texto actual

Título I: «De los derechos y deberes fundamentales"

Capítulo II: «Derechos y libertades»

\section{Texto propuesto}

"De los derechos y libertades"

"De los derechos y deberes fundamentales"

\section{JUSTIFICACIÓN}

La sistemática del constituyente para ordenar los derechos y deberes ha sido ampliamente criticada por la doctrina, $y$ ha obligado al TC a no pocas precisiones sobre el alcance de la expresión "Derechos Fundamentales». Para intentar disminuir la distancia entre los epígrafes relativos a los derechos y su contenido, proponemos un cambio de denominaciones: que el Título I se llame "De los derechos y deberes" y el Capítulo II "De los derechos y deberes fundamentales". Así no sólo se evita el contrasentido de que un capítulo intitulado "derechos y libertades" luego tenga una sección referida a los "deberes" sino que, además, se logra un criterio objetivo para distinguir entre derechos y derechos fundamentales con arreglo al "criterio de fundamentalidad" que nos proporciona el art. 53: bajo este segundo epígrafe se agrupan todos los que tienen reconocido un contenido esencial vinculante directamente ?

La actual denominación de las secciones de este Capítulo II puede

1 Dicho con la brillantez de Pedro CRUz VILLALón: «Si existen hoy día algunos elementos o datos que hagan recognoscibles a los derechos fundamentales como categoría, éstos son la tutela judicial y el respeto de su contenido esencial por el legislador" ("Formación y evolución de los derechos fundamentales", REDC, núm. 25, enero-abril de 1989, pág. 39). Jean Rivero se ha extendido en destacar que el problema común más esencial que se presenta hoy a las jurisdicciones constitucionales es precisamente la noción misma de derecho fundamental $y$, en consecuencia, el de la determinación de su contenido y aquellos que deben protegerse al más alto nivel. Pese al uso anfibológico e impreciso que el Tribunal Constitucional español ha realizado de esta expresión, buena parte de la doctrina ha despejado del modo más claro y razonable esta incógnita en nuestro Derecho constitucional en el mismo sentido indicado por Cruz Villalón. Citamos, por todos, los trabajos de J.R. Cossio Díaz: Estado social y derechos de prestación. Madrid, CEC, 1989, especialmente págs. 58 y ss.; de J.J. SolozÁBAl ECHEVARRía: «Algunas 
que no sea muy satisfactoria; pero nos inclinamos por mantenerla en primer lugar porque no hemos sido capaces de encontrar unas expresiones más adecuadas para distinguir dentro de los derechos fundamentales ${ }^{2} y$, en segundo, porque así es posible mantener la doctrina del TC sobre la reserva de ley orgánica sin necesidad de tener que modificar per relationem el artículo 81 de la Constitución.

\section{SOBRE LA SISTEMÁTICA}

1. Deberían incorporarse a la Sección Primera tanto el artículo 14 como el 30 .

2. La Sección II debería reordenar su articulado de la siguiente forma:

cuestiones básicas de la teoría de los derechos fundamentales», REP, núm. 71, enero-marzo, 199. Esta concepción de la "fundamentalidad" de los derechos es la que oportunamente late también en el voto particular del magistrado F. Rubio Llorente a la controvertida STC 26/87, al que se adhiere el magistrado E. Díaz Eimil, así como en las reflexiones que el magistrado L. Díez-Picazo realiza a la luz de la experiencia de diez años de práctica jurisdiccional constitucional, al afirmar que ahora se inclina a pensar que son derechos fundamentales todos los comprendidos en el Capítulo II («La jurisprudencia constitucional de los derechos fundamentales, 5 . En la obra colectiva dirigida por A. LóPEz PINA: La garantía constitucional de los derechos fundamentales: Alemania, Francia, España, Italia. Madrid, Civitas, 1991.). Sobre este tema, uno de nosotros ha realizado reflexiones más amplias, aún inéditas (G. CÁmARA VILLAR: El voto particular en materia de derechos fundamentales en la práctica del Tribunal Constitucional español (1981-1991), especialmente Capítulo I de la Segunda parte: "Definición del campo de estudio: concepto de derechos fundamentales"). En conclusión, llevar este acuerdo doctrinal mayoritario y clarificador a la oscuridad de algunas de las rúbricas constitucionales del Título I es el objetivo de nuestra particular "enmienda».

2 He aquí algunas, divisiones que hemos rechazado: "derechos esenciales/ordinarios", "derechos subjetivos/derechos y deberes", "especialmente protegidos/de normal protección», "Garantías individuales y políticas/Familia, economía y cultura» (esta última división tomada de la Constitución de 1931). 
Contenido

Matrimonio

Propiedad

Fundación

Sist. tributario

Trabajo

Libertad de empresa

Colegios Profs.

Convenios y conflictos
Núm. que se propone

31

32

33

34

35

36

Supresión

37
Art. actual

32

33

34

31

35

38

36

37

\section{JUSTIFICACIÓN}

1. El artículo 14 consagra un derecho subjetivo que, aunque no autónomo, tiene el mismo régimen de tutela jurisdiccional que los contenidos en la Sección 1.a; por otra parte, no se comprende cómo el derecho a la igualdad, manifestación directísima de un valor superior del ordenamiento, puede tener un grado de protección (reforma ordinaria) inferior a otros derechos mucho más secundarios tanto desde un punto de vista axiológico como de aplicación cotidiana, tales como el derecho de petición y la prohibición de tribunales de honor.

La única objeción que quizá podría hacerse a la inclusión del artículo 14 en la Sección 1. ${ }^{a}$ consiste en que de esa manera se pierde el carácter de "pórtico" del Capítulo I. Nada podríamos replicar a esa objeción si se afirmase desde un punto de vista puramente estético, pero desde el jurídico sería inadecuado intentar sacar cualquier conclusión, pues si la igualdad se aplica hoy a los derechos de la Sección $2 .^{a}$ no es porque el artículo 14 esté fuera de la Sección 1. ${ }^{a}$, sino porque la igualdad alcanza a cualquier derecho, como se comprueba con sólo pensar en el sinsentido que sería argumentar que el legislador podría regular discriminatoriamente un derecho social del capítulo III, o más lejos aún, un derecho extravagante como el derecho de acceso a los archivos (art. 105) o la gratuidad de la justicia (art. 119). 
El artículo 30 se refiere, básicamente, a la polémica cuestión de las obligaciones militares y la objeción de conciencia. Aunque se caiga en la pequeña incongruencia de introducir un deber en la sección 1. ${ }^{\mathrm{a}}$, parece conveniente hacerlo así para exigir que se desarrolle por ley orgánica la regulación de obligaciones de índole personalísima. Cuestión que, por lo demás, ya sucede en parte con la Ley Orgánica 4/1981, de 1 de junio, de los estados de alarma, excepción y sitio y lo ha considerado exigido un importante sector doctrinal para regular la objeción de conciencia (incluso en el voto particular de la STC 161/1987, de 27 de octubre).

Por otra parte, al incluir el artículo 30 en la Sección $1 .^{a}$ se dota de una indudable base constitucional a la actual tutela judicial de la objeción de conciencia por el procedimiento preferente y sumario de los derechos fundamentales que, como se sabe, la LO 4/1984 le atribuye, a pesar de que el art. 53.2 de la CE únicamente se refiere al recurso de amparo.

De seguirse nuestra propuesta en torno a estos dos puntos, es evidente que debería también ser modificado, por relación, al artículo 53.2, del cual tendrían que desaparecer las referencias específicas tanto al artículo 14, como al 30.2, deshaciéndose así su actual inconveniente complejidad. Tal sería su tenor literal: "Cualquier ciudadano podrá recabar la tutela de las libertades y derechos reconocidos en la Sección Primera del Capítulo Segundo ante los Tribunales ordinarios por un procedimiento basado en los principios de preferencia y sumariedad $y$, en su caso, a través del recurso de amparo ante el Tribunal Constitucional".

2. La Sección 2. a del Capítulo II no se caracteriza, precisamente por su sistemática: el matrimonio (art. 32) aparece entre las obligaciones fiscales (art. 31) y el derecho a la propiedad privada (art. 33), se garantiza el derecho a la negociación colectiva de trabajadores y empresarios (art. 37) antes de reconocer la libertad de empresa (art. 38), etc.

Por eso, proponemos una nueva ordenación más lógica: en primer lugar deben figurar los derechos personales, el matrimonio y la propiedad (con su inesperado ahijado de la era industrial, el derecho de fundación); a continuación, las obligaciones fiscales, que tienen sentido después de reconocer la propiedad privada; para terminar con los artículos referentes al mundo laboral: derecho al trabajo, libertad de empresa, y convenios colectivos. El artículo 36 debería derogarse pues no parece - como demuestra el derecho comparado- que los Colegios Profesionales sean materia constitucional. 


\section{EVALUACION Y PROPUESTAS}

DE REFORMA DEL ARTICULADO: arts. 14, 15, 16, 18, 19, 20 , $21,26,27,29,30,31,33,34,35$ у 38.

Art. 14

Texto actual

"Los españoles son iguales ante la ley, sin que pueda prevalecer discriminación alguna por razón de nacimiento, raza, sexo, religión, opinión o cualquier otra condición o circunstancia personal o social.»

\section{Propuesta}

"La ley no hará excepción arbitraria de personas y se aplicará igualmente a todos. Los españoles tienen derecho a la igualdad sin que pueda prevalecer discriminación alguna por razón de nacimiento, raza, sexo, religión, opinión o cualquier otra condición o circunstancia personal o social."

\section{JUSTIFICACIÓN}

La igualdad jurídica ha sido uno de los temas que más ha ocupado tanto a la jurisprudencia constitucional como a la doctrina. La discusión teórica ha dado sus frutos en una serie de pautas interpretativas que comparte la mayoría de la doctrina: es un auténtico derecho subjetivo y no sólo un principio, entre sus destinatarios se incluye el poder legislativo, su alcance normativo no prohibe las leyes ad personam ni las diferencias de trato, sino únicamente las irrazonables, las causas de discriminación ilegítima son numerus apertus, etc.

Pues bien, con nuestra propuesta intentamos que en la propia Constitución se evidencien esos criterios. Por eso, constitucionalizamos la igualdad tanto en la ley como en su aplicación, pero admitiendo que ello no implica una igualdad puramente formal, sino que son posibles las regulaciones diferentes siempre que estén justificadas. De la misma forma, usamos la expresión "derecho a la igualdad" para resaltar que se trata de un derecho subjetivo, si bien no es autónomo. Hemos preferido no añadir a continuación "ante la ley" no sólo porque ya lo expresa la primera frase de nuestra propuesta, sino para resaltar que vincula a todos los poderes públicos. 
La cuestión práctica en la que hoy día hay menos acuerdo doctrinal es en el juicio de razonabilidad. Casi toda la doctrina coincide con el TC en dos criterios esenciales: el fin y los efectos proporcionales de la norma; sin embargo, cuando se trata de aplicar a un caso concreto no siempre se llega a idéntica conclusión, incluso en el mismo seno del TC. Así, si para la mayoría no vulnera la igualdad la Ley $48 / 1984$ cuando establece un plazo de 24 meses del servicio civil frente a los 12 del militar, sí lo considera así la minoría ${ }^{3}$; o mientras unos consideran que es un trato desigual irrazonable y arbitrario que el Decreto $2530 / 1970$ prive a las cotizaciones extemporáneas de efectos para obtener la pensión de vejez en el régimen de trabajadores autónomos, para otros está justificado y no viola el artículo 144 .

No parece posible que ninguna norma, por muy detallada que sea, pueda evitar a priori estos conflictos interpretativos. Por eso, no se nos escapa lo insuficiente que resulta la introducción en nuestra propuesta de la referencia a las "excepciones arbitrarias". Al incluir este concepto jurídico indeterminado sólo hemos pretendido constitucionalizar los criterios y técnicas específicamente desarrollados jurisprudencialmente, como son los denominados juicios o tests de racionalidad, razonabilidad, adecuación y proporcionalidad, entre otros, ligados a la jurisprudencia de valores, que permiten un trabajo de maestría jurídica y remiten, más allá de la Constitución, como dice RUBIO LLORENTE, "a un juicio de la razón práctica: la decisión sobre la validez de las diferencias establecidas por el legislador" 5; criterios todos ellos reconducibles al de razonabilidad en sentido amplio, tan usado no sólo por nuestro TC sino por todas las jurisdicciones constitucionales occidentales (la reasonable basis del Tribunal Supremo americano, la regla de la ragionevolezza italiana, etc.).

El artículo 14 consagra uno de los pocos derechos constitucionales dirigido expresamente a "los españoles". No hemos considerado conveniente cambiar el sujeto porque es evidente que en el estado actual de desarrollo de las relaciones internacionales no parece posible suprimir ciertas normas diferenciadoras (empezando por algunos artículos constitucionales). Pero en la línea de intentar que los derechos fundamentales sean los mismos para todas las personas hemos redactado el primer inciso de este artículo 14 de forma general. Así no se evita que la condición de

3 Vid. STC 160/1987, de 27 de octubre y la discrepancia sobre esta cuestión expresada en los votos particulares de los magistrados De la Vega Benayas, García-Mon y Rodríguez-Piñero.

4 Vid. la STC 189/1987, de 24 de noviembre y los votos particulares de los magistrados Díaz Eimil (al que se adhieren Latorre Segura, Truyol Serra y Rodríguez-Piñero) y Rubio Llorente.

5 Francisco RUBio LlORENTE: "La igualdad en la jurisprudencia del Tribunal Constitucional», REDC, núm. 31, enero-abril de 1991, pág. 31. 
extranjero pueda ser origen de diferencias normativas en relación con los españoles, pero sí que lo sea sin ningún fundamento ${ }^{6}$.

Algunos autores han abogado por la conveniencia de aumentar la lista de condiciones vedadas del artículo 14 , aún reconociendo que se trata de un numerus apertus; muy especialmente se ha notado la falta de mención de la lengua como una circunstancia que no puede ser tomada en cuenta como fundamento de discriminaciones. En los debates constituyentes ya se advirtió esa ausencia, que rompe con el paralelismo del artículo 14 con los textos internacionales ${ }^{7}$.

Pero, precisamente, tanto el carácter abierto de la lista como el hecho de que la Declaración Universal de los Derechos Humanos (art. 2:1) y el Convenio europeo para la protección de los derechos humanos (art. 14) lo recojan explícitamente, hacen jurídicamente innecesaria su especificación; más aún si se recuerda que la causa última de su ausencia se debe, con toda probabilidad, al deseo de no dificultar una política de tutela y protección de las lenguas minoritarias.

6 Con ello no se haría sino racionalizar el texto constitucional conforme a sus propios principios y a la interpretación realizada por nuestro Tribunal Constitucional. Vid., en este sentido, la STC 107/1984, de la que extraemos las siguientes precisiones: «...existen derechos que corresponden por igual a españoles y extranjeros y cuya regulación ha de ser iguai para ambos..."; así sucede con aquellos derechos fundamentales que "pertenecen a la persona en cuanto tal y no como ciudadano», es decir, con "aquellos que son imprescindibles para la garantía de la dignidad humana que conforme al art. 10.1 de nuestra Constitución constituye fundamento del orden político español» (f.j. tercero). En cualquier caso, la diferenciación que se establezca entre los ciudadanos y los extranjeros debe ser siempre razonable, sin que puedan resultar discriminados sin una causa constitucionalmente apreciable.

7 Cfr. las enmiendas debatidas en el Senado núms. 8, 323 y 662 en Constitución española. Trabajos parlamentarios, tomo II, Madrid, 1980, págs. 2673, 2804 y 662, respectivamente. Sobre la conveniencia de introducir este criterio cfr. Gustavo Suárez Pertierra: "Comentario al artículo 14", en Óscar Alzaga (dir.), Comentarios a las leyes políticas, Madrid, Edersa, 1984, pág. 285. 
Art. 15

\section{Texto actual}

"Todos tienen derecho a la vida y a la integridad física y moral, sin que, en ningún caso, puedan ser sometidos a tortura o tratos inhumanos o degradantes. Queda abolida la pena de muerte, salvo lo que puedan disponer las leyes penales militares para tiempos de guerra."

\section{Propuesta}

"Se garantizan los derechos a la vida y a la integridad física y moral de todas las personas, sin que, en ningún caso, puedan ser sometidas a tortura o a tratos inhumanos o degradantes. Queda abolida a la pena de muerte, salvo lo que puedan disponer las leyes penales militares para tiempos de guerra.»

\section{JUSTIFICACIÓN}

Con la supresión de la expresión "todos tienen derecho a la vida" y su sustitución por la fórmula propuesta, consideramos que se contribuiría de manera notable, entre otros temas, a clarificar jurídicamente el debate sobre la cuestión del aborto (otra cosa serían, evidentemente, los problemas ideológicos y políticos aparejados, y por ello, la viabilidad de una tal reforma), especificándose de manera inequivoca en el texto constitucional que son sólo "las personas" ( $y$ el nasciturus manifiestamente no lo es), los sujetos del derecho a la vida.

Nos encontramos en este caso, como es conocido, ante uno de los supuestos social y políticamente más conflictivos y jurídicamente más controvertidos, en tanto que lo que está en cuestión es la colisión que se produce entre un presunto derecho a la vida del nasciturus, o una exigencia de orden público general que afecta a los fundamentos de la vida (su protección), con los derechos de la mujer embarazada (protección de su vida o de su dignidad, libertad e intimidad personales); tema en cuya consideración, como dice el Tribunal Constitucional, «inciden con más profundidad que en ningún otro, ideas, creencias y convicciones morales, culturales y sociales" ${ }^{8}$. Nada de extraño tiene, en consecuencia, que precisamente sea en este tema donde quepa hallar una línea de interpretación disidente alternativa dentro del propio Tribunal, así como discrepancias diversas y muy acusadas en relación a su modus operandi en lo concerniente al tratamiento que da a esta materia, y también en lo relativo a su

8 STC 23/1985, de 15 de febrero. 
posición como órgano en el sistema constitucional. Lo mismo ha sucedido, en un clima de conflicto social y político semejante, en otros países de nuestra área cultural, $y$ en todos ellos puede observarse que la respuesta jurídica está profundamente marcada y orientada por el conflicto ideológico y social subyacente, tendiendo las jurisdicciones constitucionales a proporcionar soluciones de compromiso que, por ser tales, además de alterar notablemente el marco político de ejercicio de su función, acaban siendo fuertemente contestadas desde las dos posiciones básicas en conflicto. Recuérdese la resolución del caso Roe $v$. Wade ${ }^{9}$ en Estados Unidos y, especialmente, la Sentencia del Tribunal Constitucional Federal Alemán de 25 de febrero de 1975, donde los argumentos de la mayoria y de los jueces discrepantes son, en sus líneas más generales, de similar entidad a los posteriores de nuestros magistrados, en el centro de los cuales siempre se encuentra el debate acerca de la naturaleza de la interpretación de las normas constitucionales y de la función del juez ${ }^{10}$. Lo mismo podría decirse, salvo, obviamente, en lo relativo a los votos discrepantes, de la sentencia 27/1975 del Tribunal Constitucional italiano a propósito de la constitucionalidad del art. 546 del Código Penal ${ }^{11 .}$

Nuestro Tribunal, si bien de forma poco clara, ha seguido la interpretación según la cual el nasciturus no puede ser sujeto de derechos por

$9 \quad 410$ U.S. 113.163 (1973).

10 En definitiva, la asunción por el Tribunal de un papel que no le corresponde a él, sino al legislador. Cfr. James CASEY: "El derecho al aborto en el derecho constitucional comparado". Anuario de Derecho Público y Estudios Políticos, n. ${ }^{\circ}$, Universidad de Granada, 1989-1990, págs. 345 y ss. J.P. SCHNEIDER: "Contenido y método en las sentencias comparadas sobre el aborto" y Gonzalo RoDRíGuEz MouRULLo: "La Sentencia del Tribunal Constitucional español (sobre el aborto) desde las perspectivas constitucional y penal", trabajos ambos contenidos en la obra editada por Antonio LóPEZ PINA: División de poderes e interpretación. Hacia una teoría de la praxis constitucional. Madrid, Tecnos, 1987, págs. 195-198 y 186-193, respectivamente. Hans G. RuPP: "El tribunal Constitucional Federal Alemán", en L. FAVOREU et alii: Tribunales constitucionales europeos $y$ derechos fundamentales. Madrid, CEC, 1984, págs. 337-338; en la misma obra colectiva, G. ZAGREBELSKY: «EI Tribunal Constitucional italiano", págs. 424-426. Sin embargo, como precisa OEHLINGER, el Tribunal Constitucional austríaco manifiesta que este derecho (no regulado expresamente, como se sabe, por la Ley Fundamental del Estado) del art. 2 de la Convención Europea no protege la vida más que desde el momento del nacimiento, no oponiéndose en consecuencia a la liberalización del aborto, lo que le ha permitido evitar una respuesta categórica acerca de si el Estado debe abundar en una política de protección general de la vida, incluso penalizando todo atentado contra cualquier manifestación de ésta (Theo OEHLINGER: «El Tribunal Constitucional austríaco", en la obra colectiva citada, Tribunales constitucionales..., págs. 501-502).

11 Cfr. Leopoldo Elía: "Liberalización legislativa, referéndum y jurisprudencia constitucional en Italian, en la obra editada por A. LóPEZ PINA, cit., División de poderes e interpretación..., págs. 193-194. 
no ser persona (STC 23/1985, según interpretación prefigurada por el voto particular de Tomás y Valiente a la STC 75/1984). No podría ser de otra manera, pues un derecho muy extraño sería el derecho a nacer 0 al nacimiento, como subraya ZAGREBELSKY, con un sujeto jurídico que todavía no existe y que, precisamente cuando llegue a existir el derecho ya se ha extinguido. Más conviene a esta situación jurídica de protección de la vida humana intrauterina, por consiguiente, su calificación como «exigencia de orden público general que afecta directamente a los fundamentos de la vida humana en común y de su prolongación en el tiempo" ${ }^{12}$.

En definitiva, no hay un derecho a la vida como derecho al nacimiento, sino un derecho a la vida de los nacidos, que se concreta en el derecho a la propia existencia psicológica y a un modo de vivir humano ${ }^{13}$, cuyo reflejo determina el carácter de bien constitucionalmente protegido de los que son todavía sólo spes hominis. El derecho a la vida es un derecho de libertad que garantiza al individuo, fundamentalmente, una protección frente a la reglamentación y tutela estatales, cuya confusión con la vida como principio ontológico de existencia puede acarrear las más grandes disfunciones, sobre todo en el plano jurídico, introduciendo en la interpretación constitucional el discurso de la ética en detrimento del razonamiento jurídico.

Mediante la reforma que proponemos se impediría esta interpretación y la predeterminación por esta vía de posibles soluciones de futuro a emprender en otra dirección por el legislador en relación a la actualmente vigente (v. gr., la introducción de un cuarto supuesto de estado de necesidad, la indicación "social", o una ley de plazos). Porque las obligaciones de protección del Estado son en este caso "reflejo" del derecho a la vida y no aplicación directa del mismo, sólo accesibles mediante interpretación. El Tribunal Constitucional, deduciendo de su posición constitucional todas sus consecuencias, no se vería abocado, presionado o tentado en estos casos a crear Derecho Constitucional, preservándose así el ámbito reservado al legislador $y$, en definitiva, la apertura constitucional básica y fundamental en determinados temas que sólo políticamente pueden tener una respuesta adecuada.

12 Gustavo Zagrebelsky: "El Tribunal Constitucional italiano», op. cit., páginas $424-425$.

13 Gonzalo Rodríguez Mourullo: "Derecho a la vida». Comentario al art. 15 C.E., en Óscar AlzAGA (Dir.): Comentarios a las leyes políticas. Constitución española de 1978, tomo Il, Madrid, Edersa, 1984, pág. 314. 


\section{Texto actual}

"1. Se garantiza la libertad ideológi$\mathrm{ca}$, religiosa y de culto de los individuos y las comunidades sin más limitación, en sus manifestaciones, que la necesaria para el mantenimiento del orden público protegido por la ley.

2. Nadie podrá ser obligado a declarar sobre su ideología, religión o creencias.

3. Ninguna confesión tendrá carácter estatal. Los poderes públicos tendrán en cuenta las creencias religiosas de la sociedad española y mantendrán las consiguientes relaciones de cooperación con la Iglesia Católica y las demás confesiones."

\section{Propuesta}

"1. Se garantizan las libertades de conciencia, ideológica, religiosa y de culto de las personas y las comunidades, sin más limitación en su manifestación que la necesaria para el mantenimiento del orden público protegido porla ley.

2. Nadie podrá ser obligado a declarar sobre su ideología, religión o creencias.

3. Ninguna confesión tendrá carácter estatal."

\section{JUSTIFICACIÓN}

Como escribe KRIELE, y con él casi toda la doctrina, la libertad religiosa fue "la primera libertad", aquella que sembró el anhelo del Estado constitucional para acabar con las guerras de religión que asolaron Europa en la Edad Moderna ${ }^{14}$. Pero esta afirmación, cierta con carácter general, lo es menos en el caso español, donde las Constituciones del siglo XIX silenciaron esta libertad cuando no declararon rotundamente, como la de 1876, que "La religión católica, apostólica y romana es la del Estado». Para compensar, la Constitución de 1931 garantizaba la libertad religiosa pero sus artículos 26 y 27 establecían una regulación rabiosamente anticatólica: prohibición a todos los poderes públicos de financiar las Iglesias, disolución de los jesuitas, prohibición a las órdenes religiosas de ejercer la industria, el comercio o la enseñanza, etc., etc.

Con esos precedentes, no puede extrañar que en los debates consti-

14 Martin Kriele: Introducción a la Teoría del Estado. Buenos Aires, Editorial Depalma, 1980, pág. 3. 
tuyentes la cuestión religiosa fuera un motivo de división política. Afortunadamente, los tiempos en los que los españoles siempre iban detrás de los sacerdotes - unas veces en procesión, otras persiguiéndolos- habian pasado a la Historia y el asunto se afrontó con menos pasión y más realismo que antaño; tanto es así que el centro del enfrentamiento fue no tanto la redacción de la libertad de religión, como la de enseñanza. El equilibrio se logró en el art. 16.3 con el método clásico del consenso: mientras las fuerzas laicas introducían la mención a la aconfesionalidad del Estado, las clericales agregaban la obligación de los poderes públicos de cooperar con la Iglesia católica y las demás confesiones.

Así las cosas, el debate sobre la reforma del artículo 16 se centraría, ineluctablemente, en la redacción que deba darse a su apartado tercero. Los otros dos, a nuestro juicio, sólo admiten pequeños retoques de estilo: emplear el plural, puesto que se trata de derechos distintos, añadir la «libertad de conciencia" —que ahora se sobreentiende- y cambiar el término "individuos" por el más jurídico "personas».

$Y$ centrándonos en ese apartado tercero, nos hemos inclinado por la supresión integra de la segunda frase, para que desaparezca cualquier referencia a las relaciones de cooperación de los poderes públicos no sólo con la Iglesia católica, sino también con las demás religiones. No se trata, por tanto, de discutir si la mención de la Iglesia católica supone una confesionalidad encubierta, como se alegó en algún momento del debate constituyente, porque la primera frase del artículo 16.3 garantiza la neutralidad religiosa del Estado, sino de avanzar en la separación de la política y la religión.

Tal y como está ahora redactado este artículo 16.3, además de consagrar esa neutralidad religiosa, establece un mandato a los poderes públicos para cooperar con las distintas confesiones (STC 93/1983, de 8 de noviembre). Pues bien, nuestra propuesta consiste en hacer desaparecer ese mandato no para prohibir la colaboración, sino para que ésta se establezca, o no, según lo que decidan en cada momento los poderes públicos emanados de la voluntad popular. Dicho con otras palabras: lo que pretendemos es que tanto un partido que lleve en su programa electoral subvencionar a las religiones, como otro que no, puedan realizar su política en caso de que reciban el apoyo popular, sin verse constreñidos por un mandato constitucional. 
Art. 18

\section{Texto actual}

“1. Se garantiza el derecho al honor,....

«3. Se garantiza el secreto de las comunicaciones $y$, en especial, de las postales, telegráficas $\mathrm{V}$ telefónicas, salvo resolución judicial.»

\section{Propuesta}

[Añadir un nuevo epígrafe]:

“2. Se prohiben los Tribunales de Honor de cualquier tipo"

[Nueva numeración de los demás apartados]

"4. Se garantiza la libertad e inviolabilidad de las comunicaciones privadas y en especial..."

\section{JUSTIFICACIÓN}

Recoge el artículo 18 una amplia gama de derechos para defender la esfera íntima de las personas. Lo hace con tal exhaustividad que, desde el punto de vista de su hipotética reforma, las opiniones doctrinales se reducen a considerar aspectos que no afectan sustancialmente a estos derechos personalísimos: lo superfluo de la referencia "a la propia imagen", ya contenido en el derecho a la intimidad; el olvido de la fuerza mayor o estado de necesidad como causa habilitante para entrar en un domicilio; la inexactitud de referirse al "secreto de las comunicaciones" cuando se trata de un derecho a su «inviolabilidad", etc. No estamos muy seguros de que sea necesario hacer todos esos cambios, pues podrían dar pie a una reducción de los derechos (si se suprime la referencia expresa a la imagen) o a cierta imprecisión (el estado de necesidad es una causa de justificación de la responsabilidad penal que no sólo tiene consecuencias en la tutela de este bien constitucional).

Quizá la propuesta que debería hacerse es, como ha razonado TORRES DEL MORAL 15, la de sustituir en el párrafo tercero "secreto" por «inviolabilidad»; agregamos nosotros - sin mas ánimo que la de aumentar la precisión lingüística- la vertiente positiva («libertad de las comuni-

15 Antonio ToRres del Moral: Principios de Derecho Constitucional Español, 2. ${ }^{\circ}$ ed., Madrid, Átomo, 1988, pág. 253. La referencia que hacemos enseguida al TC es por su STC 114/1984, de 29 de noviembre. 
caciones") que ahora está ínsita en la redacción del artículo 18.3 según ha señalado el mismo TC.

En el ámbito de la aplicación práctica, los problemas que el artículo 18 plantea son de dos tipos: por un lado la clásica concreción de conceptos jurídicos como el de "domicilio" y, derivado de la aprobación de la Ley de Seguridad Ciudadana, el de "delito flagrante"; por otro, su conflicto con la libertad de expresión. Ambos problemas son típicos problemas interpretativos que difícilmente pueden resolverse añadiendo nuevos mandatos constitucionales a un texto ya de por sí bastante detallado.

Además de nuestra pequeña enmienda terminológica creemos que por cuestión sistemática el artículo 18 debe ser el lugar donde se prohiban los tribunales de honor. Por ser un residuo de situaciones anacrónicas, desconocido en el derecho comparado, en algún momento hemos pensado en la supresión pura y simple del artículo 26 , heredero directo del artículo 95 de la Constitución de 1931, en el que se abolian todos los Tribunales de honor "tanto civiles como militares", pero nos hemos inclinado por mantenerlo, ampliando el ámbito de la prohibición, siquiera sea para reflejar una característica propia del constitucionalismo hispano, y, de paso, evitar cualquier retroceso en este campo.

Art. 19

Texto actual

"Los españoles tienen derecho a elegir libremente su residencia y a circular por el territorio nacional.

Asimismo, tienen derecho a entrar $y$ salir libremente de España en los términos que la ley establezca. Este derecho no podrá ser limitado por motivos políticos o ideológicos."

\section{Propuesta}

"1. Se reconoce la libertad de residencia y circulación en el territorio nacional.

2. Todos los españoles tienen derecho a entrar y salir libremente de España en los términos que la ley establezca. Este derecho no podrá ser limitado por motivos políticos o ideológicos."

\section{JUSTIFICACIÓN}

La libertad de residencia y circulación es un tradicional derecho de libertad ("d'aller et de venir», según la típica formulación revolucionaria) 
que en 1978 fue constitucionalizado con una extensión tal que se hace difícil imaginar cómo podría mejorarse en una futura reforma de la Constitución.

Desde luego, no creemos necesario una reforma con el fin de hacer mención expresa a los derechos de permanecer en el territorio nacional o en el extranjero (las expresivamente denominadas libertades de no salir $y$ de no entrar) porque es evidente que se encuentran incluidas en el derecho a entrar y salir libremente de España.

Igualmente, nos parece que no mejoraría nada - sino más bien todo lo contrario - tratar de cambiar el papel claramente abstencionista de los poderes públicos en la salvaguardia del derecho de residencia con la introducción en este artículo 19 de una cláusula que les otorgase una función de remover los obstáculos que lo dificultan en la práctica. Esta opinión nuestra no es producto de una creencia acérrima en las bondades del libre mercado y en la teoría del desarrollo desigual que terminaría equiparando a las zonas atrasadas - de fuerte emigración- a las más adelantadas, sino que deriva de la convicción de que una afirmación así no es conveniente en el Capítulo Il porque lejos de transformarse en un derecho de prestación, su aplicación directa naufragaría o en el Escila de considerar que se trata de una norma programática, o en el Caribdis de judicializar la política hasta un grado insufrible (imaginémonos a un tribunal ordenando a tal o cual Ayuntamiento que le proporcione vivienda o trabajo o determinado ciudadano en virtud de su derecho a elegir residencia). Sin duda, los poderes públicos tienen en la Constitución otros artículos que le permiten una intervención favorable a las zonas menos desarrolladas (art. 9.2, 40.1, 42 , 130.2 , etc.) $\vee$ para la que no es obstáculo la libertad de circulación, como el TC tuvo ocasión de declarar expresamente en su Sentencia 8/1986, de 21 de enero.

Así las cosas, a nuestro juicio la cuestión polémica que presenta el artículo 19 no radica tanto en los términos en los que está recogido el derecho de residencia y circulación, como en los titulares de él: ¿debe continuar siendo un derecho fundamental de los españoles o, por contra, debería ampliarse a todas las personas? ¿Debe seguir siendo, en virtud del art. 13.1, un derecho de configuración legal para los extranjeros o - para adecuarnos a la terminología de la STC 90/1985- un derecho atemperado por lo que determinen los tratados internacionales y la Ley interna española?

Para responder parece necesario distinguir las dos facetas esenciales de este artículo 19: por un lado, la libertad de entrada en el territorio nacional $y$, por el otro, la libertad de residencia y circulación una vez que se haya ingresado legalmente. En cuanto a la primera, ningún Estado concede un derecho incondicionado a los extranjeros a entrar libremente en 
su territorio y la opinión pública de los países desarrollados tampoco es muy favorable, siendo minoritarios los movimiento sociales («lguales en derechos", por ejemplo) que reclaman, basándose en la fraternidad universal, la libertad de entrada de los extranjeros que lo deseen. Además, los efectos demográficos, sociales y económicos de todo tipo que ello supondría aconsejan que se evite la plena equiparación constitucional de extranjeros y españoles en cuanto a la libertad de entrar y salir del territorio nacional, y que continúe regulándose dicha materia por instrumentos más flexibles como la ley o el tratado.

Ahora bien, otra consideración nos merece la libertad de residencia del extranjero una vez que ha entrado legalmente en España: ¿por qué no atribuirle la mismas garantías que se le concede al nacional para fijar su residencia y su libertad de circulación? Si vemos la actual L.O. 7/1985, sobre derechos y libertades de los extranjeros en España, observamos que, básicamente, la diferencia consiste en que el Ministerio del Interior podrá, con carácter individual, limitar el derecho de residencia y circulación de los extranjeros con diversas medidas (art. 6: presentación periódica a las autoridades, alejamiento de fronteras o núcleos de población determinados y residencia obligatoria) que parecen venir dictadas por razones de policía y seguridad que se compadecen poco con la idea de Estado de Derecho, en el que sólo el poder judicial puede tomar medidas individualizadas que restrinjan de esa forma la libertad de las personas.

Por eso, creemos que supondría un avance del Estado social y democrático de Derecho una reforma del art. 19 que tendiese a la equiparación entre nacionales y extranjeros. Par ello, nos hemos limitado a retomar el texto del Anteproyecto constitucional.

Art. 20

\section{Texto actual}

"1. Se reconocen y protegen los derechos:

a) A expresar $y$ difundir libremente los pensamientos, ideas $y$ opiniones mediante la palabra, el escrito o cualquier otro medio de reproducción.

\section{Propuesta}

"1. Se reconoce y garantiza la libertad de expresión como elemento esencial de una sociedad democrática que incluye, al menos, los siguientes derechos:

a) A comunicar y recibir información veraz y a emitir ideas $y$ opiniones por cualquier medio de difusión. 
b) A la producción y creación literaria, artística, científica y técnica.

c) A la libertad de cátedra.

d) A comunicar o recibir libremente información veraz por cualquier medio de difusión. La ley regulará el derecho a la cláusula de conciencia y al secreto profesional en el ejercicio de estas libertades.

2. El ejercicio de estos derechos no puede restringirse mediante ningún tipo de censura previa.

3. La ley regulará la organización y el control parlamentario de los medios de comunicación social dependientes del Estado o de cualquier ente público y garantizará el acceso a dichos medios de los grupos sociales y políticos significativos, respetando el pluralismo de la sociedad y de las diversas lenguas de España.

4. Estas libertades tienen su límite en el respeto a los derechos reconocidos en este Título, en los preceptos de las leyes que lo desarrollan $y$, especialmente, en el derecho al honor, a la intimidad, a la propia imagen y a la protección de la juventud y de la infancia.

5. Sólo podrá acordarse el secuestro de publicaciones, grabaciones y otros medios de información en virtud de resolución judicial.» b) A la rectificación de hechos personales considerados inexactos publicados en los medios de comunicación.

c) A la creación y difusión de obras literarias, artísticas, científicas y técnicas.

2. La ley establecerá el ejercicio de estos derechos, que suponen deberes $y$ responsabilidades, velando por el respeto de los demás derechos constitucionales y por la protección de la juventud y la infancia. En ningún caso podrán restringirse mediante la censuraprevia.

3. Sólo podrá acordarse el secuestro de publicaciones, grabaciones $y$ otros medios de información en virtud de resolución judicial.

4. Ningún medio de comunicación social podrá ser regulado en régimen de monopolio. La ley regulará el derecho a la cláusula de conciencia y al secreto profesional, protegiendo tanto la autonomía de los profesionales frente a los propietarios de los medios como el acceso de los grupos sociales y politicos significativos." 


\section{JUSTIFICACIÓN}

La redacción que el constituyente dio a la tradicional libertad de expresión, ha merecido la critica generalizada de la doctrina: reiterativo, prolijo, impreciso, asistemático... han sido alguno de los numerosos epítetos que, con razón, ha recibido.

En nuestra propuesta hemos intentado hacernos eco de esas críticas, así comenzamos por agrupar a todas las libertades de este artículo bajo el nombre tradicional $-\mathrm{y}$ comúnmente usado por el TC y la doctrina- de libertad de expresión, pero resaltando su función esencial en la sociedad democrática para hacer expreso su "valor superior o de eficacia irradiante" (SSTC 107/1988 y 121/1989).

Al relacionar los derechos en que se manifiesta la libertad de expresión hemos agrupado, como prácticamente es clamor unánime en la doctrina, los apartados a) y d). De esa forma no sólo aumenta la sistemática del texto y se suprimen repeticiones (que el constituyente intentó atemperar dando un uso poco habitual a la expresión "medio de reproducción»), sino que se realza la idea de que la veracidad sólo se refiere a la transmisión de hechos, pero no a la emisión de opiniones. Además, suprimimos dos palabras que nos parecen reiterativas: "pensamientos", que se puede considerar incluido dentro de «ideas", y "libremente», pues la libertad de expresión ya recoge en sí misma esa característica, implícita, por lo demás, en otros muchos artículos: el 21 no se refiere al "derecho de libre reunión", ni el 22 al de «libre asociación», etc.

En el apartado b) constitucionalizamos el derecho de rectificación, que el Tribunal Constitucional viene incluyendo por vía interpretativa dentro del derecho a la información, pero que parece conveniente regular de manera expresa y en apartado diferente, como demuestra que en la actualidad se encuentre desarrollado por una ley específica (la LO. 2/1984, de 26 de marzo).

No es muy afortunada la redacción del artículo $20.1 \mathrm{~b}$ ), pues no se entiende bien la diferencia que puede haber entre la "producción" y la "creación", ni siquiera si se está tratando de la libertad de creación científica o de los derechos de autor. Como, sin dificultad, la libertad de creación artística y científica se puede considerar protegida tanto por la libertad de pensamiento como por la de expresión, y el derecho de autor por el derecho de propiedad privada, podría defenderse la supresión del artículo $20.1 \mathrm{~b}$ ) sin que se resintiera ningún derecho de la intelligentzia española. El hecho de que sea un artículo sobre el que todavía no se ha pronunciado el TC avala aun más la idea de su inutilidad. 
Con ser ello cierto, sin embargo, nos inclinamos por una nueva redacción más inteligible, en la que se sustituya uno de los dos sustantivos sinónimos ("producción») por uno distinto («difusión»). El motivo que nos mueve no es sólo consagrar expresamente la libertad de ciencia (como hacen, dicho sea entre paréntesis, las Constituciones italiana y alemana) sino, también, dar un soporte constitucional a los derechos morales de los escritores y artistas sobre sus obras que ya no le pertenezcan. El supuesto puede que no sea muy frecuente, pero nuestra idea ha surgido, precisamente, de la lectura de la única STC que se refiere a este asunto (la 35/1987, de 18 de marzo), aunque el TC no se pudo pronunciar sobre el fondo: si vulneraba el derecho de creación artística de un escultor quien habiéndole comprado una obra la tenía desmontada y guardada en un almacén.

La libertad de cátedra, aunque tiene una evidente vertiente de libertad de expresión, es primordialmente una manifestación de la libertad de enseñanza, según la consideraba la Constitución de 1931 y el mismo TC ha declarado (SSTC 5/1981 y 26/1987). Por eso, en nuestra reforma la trasladamos al artículo 27.

Desde Kant sabemos que no hay derechos absolutos, y el TC así lo ha recordado con frecuencia en su jurisprudencia ${ }^{16}$. Desde esa perspectiva, es correcta la doctrina que considera que el artículo 20.4 es superfluo y que su función es más didáctica que normativa. Pero al margen de su poca afortunada redacción, lo cierto es que recoge una preocupación presente en el derecho comparado y que se remonta a la Declaración de Derecho del Hombre y el Ciudadano de 1789, en la que al reconocer la libertad de expresión se advierte que es sin perjuicio de la uresponsabilidad que el abuso de esta libertad produzca en los casos determinados en la ley" (art. 11).

Por eso, nos hemos inclinado por mantener la idea del párrafo cuarto, si bien dándole una redacción que nos parece más exacta, inspirada en el artículo 10.2 del Convenio Europeo de los Derechos Humanos y que creemos que puede reforzar las tesis doctrinales sobre la conveniencia de un cambio de rumbo en la jurisprudencia ordinaria, demasiado propensa a primar el derecho al honor sobre la libertad de expresión.

El artículo 20.3 se redactó pensando en el papel preponderante que tenía el Estado en los medios de comunicación: monopolio de la televi-

16 Cfr. SSTC 110/1984, de 26 de noviembre, 66/1985, de 23 de febrero, 159/1986, de 12 de diciembre, etc. Por toda la crítica a la jurisprudencia, a la que enseguida nos referiremos, cfr. Santiago MuÑOZ MACHADO: Libertad de prensa $y$ procesos por difamación. Barcelona, Ariel, 1988, passim. 
sión, importante participación en las emisoras de radio y la propiedad de una cadena de periódicos. Hoy día la situación ha cambiado y el Estado se bate en retirada de todos los medios (recientemente se ha anunciado la venta de su participación del 25 por 100 en la cadena SER). Por consiguiente, creemos que debe darse una nueva redacción a este artículo 20.3; comenzando, en primer lugar, por hacer una declaración expresa de la prohibición de la regulación en régimen de monopolio de cualquier medio de difusión, de tal forma que ya no sea posible la polémica sobre si tal cuestión es una "decisión política" del legislador o no, como sucedió en el propio seno del TC con motivo de un recurso de amparo sobre la libertad de antena ${ }^{17}$.

La preocupación por garantizar tanto la neutralidad de los medios de comunicación estatales como el acceso a ellos de los grupos sociales y políticos que tuvo el constituyente debe ampliarse en la actualidad, porque los ataques a la libertad de comunicación no parten únicamente de los poderes públicos, sino también de los privados, como se puede observar casi a diario. Para evitarlo, en la medida de lo posible, hemos incluido en este artículo 20.4 el actual mandato al legislador de regulación de la cláusula de conciencia y el secreto profesional. Además, se constitucionaliza la autorización de otras técnicas (publicación periódica de los propietarios, topes máximos en la adquisición de acciones, etc..) que el legislador estime pertinentes para garantizar la autonomía de los profesionales de la información frente a los propietarios, sin distinguir si éstos son públicos o privados.

Art. 21

Sin modificaciones

JUSTIFICACIÓN

Regula nuestra Constitución el derecho de reunión, uno de los primeros derechos políticos hoy venido a menos, siguiendo el criterio con-

17 STC 12/1982, de 31 de marzo. Voto particular del magistrado Rubio Llorente. Cfr. sobre esta cuestión el interesante comentario de F.J. BASTIDA FREIJEDO: "La libertad de difusión en el artículo 20.1 de la Constitución: la libertad de antenan. X Jornadas de Estudio de la Dirección General del Servicio Jurídico del Estado. Introducción a los derechos fundamentales. Madrid, Ministerio de Justicia, 1988. Vol. I. 
solidado de otros textos constitucionales. Incluso mejora la terminología de éstos al emplear la expresión "lugares de tránsito público" más exacta que la del "al aire libre"; y es más generosa, porque considera sujetos del derecho a todas las personas y no únicamente a los nacionales, como es habitual en el derecho comparado ${ }^{18}$.

En esa comparación, y en el hecho de que su aplicación haya sido relativamente sencilla, nos basamos para proponer el mantenimiento de la redacción actual. Desde luego, no nos parece adecuada una reforma que, siguiendo la Constitución portuguesa, suprimiese la obligación de la comunicación previa. Quizá, por puro interés estético - más que estilísticopodría proponerse una redacción que evitara el giro «comunicación previa a la autoridad", por las resonancias autoritarias de la última palabra.

\title{
Art. 26
}

Se traslada su contenido, ampliándolo, al artículo 18.

\author{
JUSTIFICACIÓN
}

El hecho de que una norma eminentemente organizativa se encuentre como un artículo específico dentro de los derechos fundamentales se debe a una enmienda introducida en la Comisión del Congreso de los Diputados con la intención de terminar con los tribunales de honor, tan gratos al régimen franquista. El consenso hizo que no se ampliase expresamente al ámbito castrense y el desarrollo constitucional lo ha convertido en un precepto olvidado. Quizás en 1978 su sitio ideal hubiera sido una disposición transitoria y nosotros pequemos hoy de cautos al mantenerlo, aunque sea como una garantía dentro del derecho al honor.

18 Cfr. los artículos 8 y 17 de las Constituciones alemana e italiana. La STC $115 / 1987$, de 7 de julio, reconoce expresamente que los extranjeros también son titulares de este derecho de reunión y declara inconstitucional el art. 7 de la Ley de extranjería en cuanto exigía el requisito de la autorización previa. 


\section{Texto actual}

«1. Todos tienen derecho a la educación. Se reconoce la libertad de enseñanza.

2. La educación tendrá por objeto el pleno desarrollo de la personalidad humana en el respeto a los principios democráticos de convivencia y a los derechos y libertades fundamentales.

3. Los poderes públicos garantizan el derecho que asiste a los padres para que sus hijos reciban la formación religiosa y moral que esté de acuerdo con sus propias convicciones.

4. La enseñanza básica es obligatoria y gratuita.

5. Los poderes públicos garantizan el derecho de todos a la educación, mediante una programación general de la enseñanza, con participación efectiva de todos los sectores afectados y la creación de centros docentes.

6. Se reconoce a las personas físicas y jurídicas la libertad de creación de centros, dentro del respeto a los principios constitucionales.

7. Los profesores, padres y, en su caso, los alumnos intervendrán en el control y gestión de todos los centros sostenidos por la Administración con fondos públicos, en los términos que la ley establezca.

8. Los poderes públicos inspeccionarán y homologarán el sistema educativo para garantizar el cumplimiento de las leyes.

9. Los poderes públicos ayudarán a los centros docentes que reúnan los requisitos que la ley establezca.

\section{Propuesta}

Art. 27A (26, por la propuesta anterior)

"Se reconoce y garantiza la libertad de educación que comprende, al menos:

a) la libertad de creación de centros docentes,

b) la libertad de cátedra,

c) la autonomía universitaria, en los términos que la ley establezca.

d) y la libertad de los padres de escoger el tipo de educación que habrá de darse a sus hijos."

Art. 27B (27)

“1. Todos tienen el derecho a la enseñanza, que tendrá por objeto el pleno desarrollo de la personalidad humana en el respeto a los principios democráticos de convivencia.

2. Los poderes públicos garantizan este derecho mediante la creación de centros docentes, la homologación e inspección de los privados, y una programación general de la enseñanza, con participación efectiva de todos los sectores afectados.

3. La enseñanza básica es obligatoria y gratuita.

4. Los profesores, los padres y, en su caso, los alumnos, intervendrán en el control y gestión de todos los centros que reciban fondos públicos en los términos que la ley establezca.

5. Los poderes públicos respetarán el derecho de los padres a que sus hijos reciban la formación religiosa $y$ moral que esté de acuerdo con sus propias convicciones. 
Texto actual (continuación)

10. Se reconoce la autonomía de las Universidades, en los términos que la ley establezca."

\section{Propuesta (continuación)}

6. Los poderes públicos establecerán un sistema de becas para garantizar la igualdad de oportunidades educativas y ayudarán financieramente a los centros docentes que reúnan los requisitos que la ley establezca."

\section{JUSTIFICACIÓN}

No descubrimos ningún secreto si afirmamos que el artículo 27 fue el artículo referente a los derechos fundamentales más debatido en las discusiones constituyentes y donde el consenso estuvo a punto de naufragar, tanto que fue uno a propósito de los cuales se justificó el abandono temporal de la ponencia constitucional del representante socialista, Peces Barba.

La disputa hundía sus raíces en el enfrentamiento entre laicos y clericales; defensores unos de la escuela pública, laica y gratuita, y los otros de un modelo mixto pero tutelado por la jerárquica católica. De hecho, en 1978 el trasunto de la cuestión religiosa que tanto enfrentó a los constituyentes de 1931 fue, a nuestro juicio, el derecho a la educación. El acuerdo se produjo, como casi siempre, por el abandono de las posturas maximalistas y por la inclusión de propuestas de ambos lados. El resultado, como no podía ser de otro modo, fue un conglomerado yuxtapuesto de disposiciones, un compromiso apócrifo - según la consolidada expresión de SCHMITT- que no ha impedido que se repitiese los enfrentamientos al elaborar sus normas de desarrollo, finalmente solventados en sede constitucional ${ }^{19}$.

Pero si el pacto escolar no se ha podido alcanzar y las fuerzas políticas más relevantes han mantenido unas lecturas del artículo 27 de la

19 Tanto la LOECE, como el proyecto de ley de LODE y la LRU fueron recurridas ante el TC (SSTC 5/1981, 77/1985 y 26/1987). Además de éstas, otras sentencias han originado que el TC haya elaborado una desarrollada doctrina sobre el derecho a la educación. Así, pueden consultarse las SSTC 6/1982, de 22 de febrero, $87 / 1983$, de 27 de octubre, 88/1983, de 27 de octubre, $47 / 1985$ de 27 de marzo, 48/1985, de 28 de marzo, 55/1985, de 22 de abril, 5/1985, de 6 de mayo, 77/1985, de 27 de junio, 86/1985, de 10 de julio, 93/1985, de 24 de julio, 137/1986, de 6 de noviembre, 195/1989, de 27 de noviembre, y 19/1990, de 12 de febrero, entre otras. Véase sobre este tema el trabajo de A. EMBID IRUJO: "La jurisprudencia del Tribunal Constitucional sobre la enseñanza". REDC, núm. 15, septiembre-diciembre de 1985. 
Constitución muy distintas, lo cierto es que en las cuestiones generales hoy día la discrepancia es pequeña: todos admiten un modelo de enseñanza mixto, una subvención reglada a los centros concertados, la autonomía universitaria, etc.; y las diferencias, con ser importantes, se manifiestan en cuestiones que no parece adecuado resolver en sede constitucional: cheque escolar, horario de la enseñanza de la religión, etc.

Por eso, creemos que lo más adecuado para una hipotética reforma del artículo 27 sería aclarar los conceptos que ahora andan entremezclados, podar los superfluos y no restringir innecesariamente el ámbito del legislador ordinario para que pueda desarrollar la política educativa que, con la legitimidad que dan las elecciones, considere más conveniente.

Para ello, hemos comenzado por separar la libertad de educación del derecho a la enseñanza, distinción que realizamos siguiendo al Tribunal Europeo de los Derechos Humanos: la educación es la inculcación de creencias, de hábitos y valores y la enseñanza es la transmisión de conocimientos (STEDH de 25 de febrero de 1982) ${ }^{20}$. La libertad de educación, como libertad-autonomía clásica no presenta especiales problemas: todas las especificaciones que hemos recogido son aceptadas unánimemente por las fuerzas políticas y por la doctrina académica. Si acaso, existe cierta polémica sobre la configuración de la autonomía universitaria como derecho fundamental o sólo como garantía institucional; al considerarla una manifestación de la libertad de educación, reforzamos la primera tesis, defendida por la mayoría del TC en su STC 26/1987, de 27 de febrero ${ }^{21 .}$

20 Aunque, evidentemente, educación y enseñanza son fenómenos inescindibles, una misma realidad, por lo que resulta prácticamente imposible distinguirlos en la práctica. No obstante, creemos que esta distinción teórica puede resultar fructífera en el contexto de la reforma del precepto que planteamos. Sobre esta cuestión, véase el voto particular del magistrado Tomás y Valiente a la STC de 13 de febrero de 1981, así como las consideraciones críticas contenidas en G. CAMARA VILLAR: "Sobre el concepto y los fines de la educación en la Constitución española", en X Jornadas de Estudios de la Dirección General de lo Contencioso del Estado. Introducción a los derechos fundamentales. Madrid, Ministerio de Justicia, 1988, vol. III, especialmente, págs. 2177 y ss.

21 No obstante, somos conscientes de las reservas y aún del rechazo doctrinal que esta caracterización ha suscitado. En este sentido, véanse, además de los votos particulares de los magistrados Díez-Picazo y Rubio Llorente a la STC 26/1987, de 27 de febrero, los trabajos de A. SÁNCHEZ BLANCO: "El derecho fundamental a la autonomía universitaria», en el volumen colectivo Introducción a los derechos fundamentales, cit., págs. 594 y ss.; F. DE BORJA LóPEZ-JURADO ESCRIBANO: La autonomia de las Universidades como derecho fundamental: la construcción del Tribunal Constitucional. Madrid, Cuadernos Civitas, 1991; y J.J. SOLOZÁBAL ECHEVARRÍA: "Algunas cuestiones básicas de la teoría de los derechos fundamentales", $R E P$, núm. 71, enero-marzo de 1991, págs. 107-108. 
El derecho de enseñanza presenta ya más problemas, empezando por su propia naturaleza y ubicación: ¿debe mantenerse entre los derechos fundamentales $y$ las libertades públicas este prototípico derecho social? A nuestro juicio, debe mantenerse donde está, no sólo por el argumento utilitarista de que en todo el tiempo que lleva en la Sección 1.. - del Capítulo II no ha supuesto ningún inconveniente insalvable para el funcionamiento del Estado, como el que podría haberse derivado de declarar el derecho a la vivienda un derecho directamente alegable ante los tribunales; tampoco porque lo recoja la Declaración Universal de Derechos Humanos, la Biblia de los derechos fundamentales; sino que la razón esencial para que continúe como derecho fundamental es porque el sistema de escuelas y colegios es tan amplio y extendido que hace posible que allí donde haya un niño sin escolarizar se pueda exigir una solución $-y$ una responsabilidad-por la vía de la tutela judicial. Lo ideal sería que se lograse tal incremento de la riqueza social y del Estado del bienestar que todos los derechos de prestación pasaran a ser derechos completos, reivindicables directamente ante los tribunales. Mientras ese momento llega, bien está mantener el que ya se ha conseguido.

En nuestra propuesta de reforma del derecho a la enseñanza recogemos, con la terminología que nos ha parecido más adecuada, todos los párrafos del actual artículo 27. Si se desbroza su contenido se observa que casi todos son reflejo de Tratados Internacionales ${ }^{22}$. Precisamente, de ellos tomamos el pequeño añadido que hacemos a este artículo: el establecimiento de un sistema de becas. Las únicas disposiciones que no provienen de los textos internacionales son la participación de los sectores afectados en la programación de la enseñanza y en la gestión de los centros (aps. 5 y 7) y la obligación de los poderes públicos de ayudar a los centros privados que cumplan los requisitos legales (ap. 9). Pero a estas alturas del siglo parece que se trata de dos principios que han calado en la sociedad sin que los rechace ningún partido, por lo que no tiene mucho sentido suprimirlos.

22 Art. 26 de la Declaración Universal, art. 18.4 del Pacto Internacional de Derechos Civiles y Políticos, 13 del Pacto Internacional de Derechos Económicos, Sociales y Culturales, etc. 
Art. 29

Texto actual

«1. Todos los españoles tendrán el derecho de petición individual o colectiva, por escrito, en la forma y con los efectos que determine la ley."

\section{Propuesta}

«1. Se garantiza el derecho de petición individual y colectiva que se ejercerá en los términos que disponga la ley.»

2. [Sin modificación]

\section{JUSTIFICACIÓN}

Se ha dudado de la necesidad de constitucionalizar el derecho de petición, residuo de otras épocas, que tiene cada vez menos campo de actuación en el Estado de Derecho. Sin embargo, tanto por su tradición en nuestro Derecho constitucional como porque todavía tiene virtualidad ${ }^{23}$, nos inclinamos no sólo por mantenerlo, sino por ampliarlo a todas las personas; tal y como hacía el proyecto de Constitución hasta que, sin ningún título para ello, la Comisión Mixta Congreso-Senado decidiese restringirlo a los españoles.

Además, proponemos una redacción con el verbo en presente, para evitar así el contrasentido de que este derecho inofensivo sea el único que está redactado en futuro.

Art. 30

Texto actual

«2. La ley fijará las obligaciones militares de los españoles y regulará, con las debidas garantías, la objeción de conciencia, así como las demás cau-

\section{Propuesta}

(Se incluye en la Sección 1a)

«1. [Sin cambios].

2. La ley organizará la defensa militar de la forma más adecuada para los intereses nacionales, pudiendo establecer con ese fin un servicio militar

23 Cfr. la inteligente reivindicación del derecho de petición que hace Remedio SÁnChez Ferriz: Estudio sobre las libertades, Valencia, Tirant lo Blanch, 1989, págs. 286 y ss. 
sas de exención del servicio militar obligatorio, pudiendo imponer, en su caso, una prestación social sustitutoria." obligatorio. Si asi lo hiciera, también fijará la objeción de conciencia y las demás causas de su exención, regulando, en su caso, una prestación civil sustitutoria.

3 y 4 [Sin cambios]."

\section{JUSTIFICACIÓN}

Los problemas que el desarrollo del artículo 30 han planteado se limitan, prácticamente, a la regulación de la objeción de conciencia, donde las discrepancias han sido tanto políticas como jurídicas.

En otro lugar, uno de nosotros ha tratado con detenimiento el asunto y ha expuesto su interpretación de este artículo 30, no siempre coincidente con la jurisprudencia del constitucional 24. Permítasenos ahora que nos limitemos a tomarnos la licencia de reformarlo con el fin de dejar más claro lo que a nuestro juicio ya está en la Constitución: la defensa de España es un concepto que no se agota en la defensa con las armas, el servicio militar debe fijarlo el legislador pudiendo establecerlo obligatorio o profesional y la objeción de conciencia es un derecho fundamental y no una simple causa de exención del servicio militar.

\section{Art. 31}

\section{Propuesta}

1. [Sin cambios]

2. (Traslado, como apartado 3, al artículo 128)

3. (Pasa a ser el 2, sin cambios).

24 Gregorio CÁMARA VILLAR: La objeción de conciencia al servicio militar (Las dimensiones constitucionales del problema). Madrid, Civitas, 1991. 


\section{JUSTIFICACIÓN}

La primera cuestión que cabe plantearse al analizar una posible reforma del contenido del artículo 31 es si su situación en el Capítulo II es adecuada o no. La doctrina se ha dividido entre los que consideran que se trata de "un error de sistemática" y los que lo ven acertado en cuanto su situación le da un carácter garantista para el ciudadano ${ }^{25}$.

En nuestra opinión, convendría mantener una postura ecléctica: evidentemente el apartado segundo es un criterio rector del gasto público que sobra en la parte dogmática de una Constitución y donde tiene mejor encaje es en el Título VII. Su inclusión en el II, con una fórmula inédita en el derecho comparado que ha merecido el elogio doctrinal, se produjo en el Senado y quizás primó en ese momento la idea de mantener unidas las dos vertientes de ingresos y gastos estatales, planteamiento que, de haber prosperado siempre, hubiera llevado a despropósitos tan evidentes como a haber regulado el poder judicial en el artículo 24 y las elecciones generales en el 23.

Librado de su apartado segundo, no creemos que deba cambiarse la situación del artículo 31 pues se limita a recoger dos disposiciones tradicionales de las declaraciones de derechos: la obligación de contribuir a los gastos públicos y la garantía de la ley en la fijación de los tributos. El hecho de que la Constitución de 1978 imponga unos determinados principios del sistema tributario no cambia esa opinión sino que la refuerza, en cuanto garantizan la forma en que se exigirá la obligación del ciudadano a contribuir: de acuerdo a su capacidad económica y mediante un sistema tributario justo, inspirado en los principios de igualdad y progresividad, que en ningún caso tendrá alcance confiscatorio.

Precisamente las críticas doctrinales se han centrado en esa parte final del artículo y han señalado lo inexacto de los términos «capacidad económica" y "sistema tributario", asi como lo superfluo de las referencias a los principios de igualdad, progresividad y carácter no confiscatorio. De esto último no estamos muy seguros, pues considerar que basta calificar un sistema tributario como "justo" para que contenga las otras tres notas es, cuanto menos, dudoso. No es ésta la opinión, por ejemplo, de los ultraliberales -con HAYECK a la cabeza- que no consideran injusto proponer la abolición de todos los impuestos directos. Por eso, y al ser partidarios

25 La calificación crítica es de Óscar DE JUAN ASENJO: La Constitución económica española. Madrid, CEC, 1984, pág. 227, donde pueden consultarse las referencias de las opiniones favorables. 
del Estado del bienestar, nos inclinamos por mantener los principios tal y como están.

Las críticas a los otros términos son de más peso, ya que es cierto que la referencia a la "capacidad económica" podría interpretarse como una prohibición de los tributos extrafiscales; igualmente, no parece que se puede formar un "sistema" -es decir un conjunto armónico- con tres categoría tributarias tan distintas como los impuestos, las tasas y las contribuciones especiales ${ }^{26}$. Con ser ello verdad, nos inclinamos por mantener ambas expresiones porque "sistema tributario" es una forma de llamar al conjunto de tributos que ha hecho fortuna y no parece conveniente suplirlo por el más restringido "sistema impositivo". Por su parte, cambiar la capacidad "económica" por "contributiva" nos lleva a la tautología de afirmar que se contribuye según la capacidad contributiva y es innecesario desde el momento en que el TC ha dictaminado que el principio de capacidad económica "no impide que el legislador pueda configurar el presupuesto de hecho del tributo teniendo en cuenta consideraciones extrafiscales" (STC 37/1987, de 26 de marzo).

\section{Arts. 33 y 34}

(Sin cambios)

\section{JUSTIFICACIÓN}

El constituyente español acertó a configurar en fórmula feliz la concepción de la propiedad en el Estado social, de tal manera que de ser un derecho natural, según la teoría liberal, la ha transformado en un "derecho subjetivo debilitado" del cual no se puede escindir su función social. En el debate constituyente, la única cuestión que levantó cierta polémica fue relacionada con la expropiación: si debía recogerse, como hizo el Anteproyecto, que la indemnización fuese siempre previa a la expropiación. No lo hizo, y a nuestro juicio fue un acierto pues así, al remitir a la ley, se permite que el régimen normal expropiatorio sea el de previo pago, pero sin excluir las expropiaciones urgentes con pago diferido, como tuvo ocasión de teorizar el TC en el caso Rumasa (STC 166/1986, de 19 de diciembre).

26 Cfr. César Albiñana Garcia-Quintana: "Comentarios al artículo 31", en Óscar Alzaga, Comentarios a las leyes politicas, cit., tomo III, págs. 306-307. 
El derecho de fundación se encuentra muy ligado al derecho de propiedad en cuanto el liberalismo fue reticente a las fundaciones, en las que veía un residuo de sus odiadas manos muertas y un posible freno al concepto de propiedad como derecho a la plena disponibilidad de bienes. Hoy día, lejos de causar recelos, las fundaciones tienen buena imagen en nuestra sociedad y, en el ámbito constitucional, la pregunta es si realmente tienen importancia como para estar en la Norma normarum. No vemos especial exceso en ello, porque desde un punto de vista juridico la fundación tiene una entidad propia distinta de la asociación y de la empresa, y desde el punto de vista social su importancia es cada día más notoria.

Art. 35

\section{Texto actual}

«1. Todos los españoles tiene el deber de trabajar y el derecho al trabajo, a la libre elección de profesión u oficio, a la promoción a través del trabajo $y$ a una remuneración suficiente para satisfacer sus necesidades y las de su familia, sin que en ningún caso pueda hacerse discriminación por razón de sexo.»

\section{Propuesta}

“1. Todos los españoles tienen el deber de trabajar y el derecho al trabajo, a la libre elección de profesión u oficio, a la promoción a través del trabajo $y$ a una remuneración suficiente para satisfacer sus necesidades $y$ las de su familia."

\section{2. [Sin modificación]}

\section{JUSTIFICACIÓN}

La reiteración de una causa de discriminación expresamente prohibida por el artículo 14 es superflua y si pudo tener alguna justificación en 1978 , con una legislación y unos convenios colectivos plagados de normas perjudiciales para las mujeres, hoy no tiene mucho sentido mantenerla, más si se recuerda que la vía más eficaz de defensa - y por la que han llegado al TC las cuestiones de discriminación laboral- es la invocación ante los tribunales del artículo 14. De todas formas, hoy como entonces, el principal problema del derecho al trabajo no es tanto su regulación jurídica como su eficacia social y ahí el Derecho Constitucional tiene que ceder el papel protagonista a la política económica. 
Art. 38

(Sin modificación)

\section{JUSTIFICACIÓN}

El artículo 38 fue, de los artículos de la Sección 2. que estamos analizando aquí, el más polémico en los debates constitucionales, dentro y fuera de las Cortes. Ello se debió a que el Anteproyecto determinaba que el ejercicio del "derecho a la libre iniciativa económica privada" se regularía por ley "de acuerdo con los intereses económicos generales". La decisión final compatibilizó la economía de mercado con la posibilidad de la iniciativa pública en una fórmula que dejó satisfechos a los partidos que defendian "modelos de sociedad" distintos. Si el artículo 38 tuvo entonces la virtualidad de ser aceptado, hoy cuando los famosos "modelos" parecen cosa de la Prehistoria no advertimos ninguna razón, ni política ni jurídica, para modificar esta norma básica de la Constitución económica. Por otra parte, la interpretación de este precepto no ha producido grandes disentimientos ni en la doctrina científica ni en la jurisprudencia constitucional ${ }^{27}$.

27 No obstante, sería preciso consultar dos votos particulares de gran interés dogmático, formulados ambos por el magistrado Díez-Picazo. El primero, a la STC 37/1981, de 16 de noviembre (al que se adhieren Diez de Velasco y Fernández Viagas), y el segundo a la STC 49/1988, de 22 de marzo, donde se plantean importantes matices en lo que se refiere a la compatibilización de las perspectivas de la libertad de empresa como libertad central institucional del sistema económico con su dimensión de derecho subjetivo (libertad de organización, inversión y contratación del empresario). 